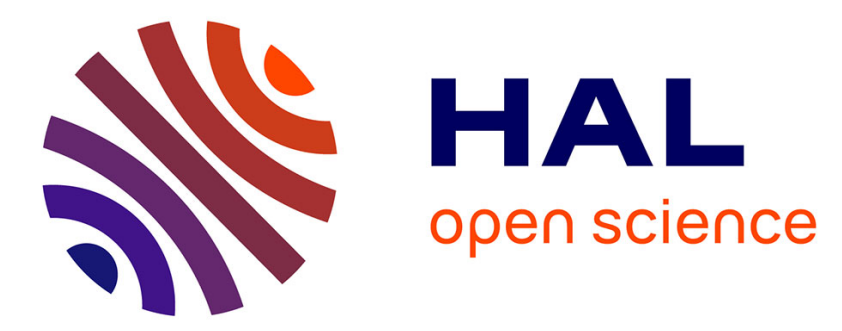

\title{
Reproductive ecology of Pinus nigra in an invasive population: individual- and population-level variation in seed production and timing of seed release
} Shaun Coutts, Caplat, Cousins, Ledgard, Yvonne Buckley

\section{- To cite this version:}

Shaun Coutts, Caplat, Cousins, Ledgard, Yvonne Buckley. Reproductive ecology of Pinus nigra in an invasive population: individual- and population-level variation in seed production and timing of seed release. Annals of Forest Science, 2012, 69 (4), pp.467-476. 10.1007/s13595-012-0184-5 . hal00930835

\section{HAL Id: hal-00930835 https://hal.science/hal-00930835}

Submitted on 1 Jan 2012

HAL is a multi-disciplinary open access archive for the deposit and dissemination of scientific research documents, whether they are published or not. The documents may come from teaching and research institutions in France or abroad, or from public or private research centers.
L'archive ouverte pluridisciplinaire HAL, est destinée au dépôt et à la diffusion de documents scientifiques de niveau recherche, publiés ou non, émanant des établissements d'enseignement et de recherche français ou étrangers, des laboratoires publics ou privés. 


\title{
Reproductive ecology of Pinus nigra in an invasive population: individual- and population-level variation in seed production and timing of seed release
}

\author{
Shaun R. Coutts $\cdot$ Paul Caplat $\cdot$ Katrina Cousins • \\ Nick Ledgard • Yvonne M. Buckley
}

Received: 3 October 2011 / Accepted: 18 January 2012 /Published online: 23 February 2012

(C) INRA / Springer-Verlag France 2012

\begin{abstract}
- Context The details of fecundity, such as its distribution and timing, can have important consequences for forest dynamics.

- Aims We detail two aspects of the reproductive ecology of an exotic population of Pinus nigra in New Zealand. We compare our findings with those reported for P. nigra in southern France and Britain.

- Methods We describe variation in fecundity, both within the population and through time, and relate seed release to climatic conditions.

- Results On average, trees entered reproduction earlier than reported in European studies. Although the mean number of cones per tree varied through time, the distribution of cone production among trees was consistently best described using a negative binomial or mixed gamma-exponential distribution. Both distributions are right skewed and trees maintained fecundity hierarchies over time, suggesting that some trees in the population have much higher lifetime reproduction than others. We found that trees released significantly more seeds when conditions were dry and windy, potentially increasing the proportion of seeds that disperse long distances.
\end{abstract}

Handling Editor: Eric Rigolot

Contribution of co-authors Paul CAPLAT, field work and editing of manuscript. Katrina COUSINS, field work, lab work and editing manuscript. Nick LEDGARD, information about Mt Barker history, field work. Yvonne M. BUCKLEY, field work, statistical advice and editing of manuscript.

S. R. Coutts $(\bowtie) \cdot$ P. Caplat $\cdot$ K. Cousins $\cdot$ N. Ledgard

Y. M. Buckley

School of Biological Sciences, University of Queensland,

Building 8, Brisbane, QLD 4072, Australia

e-mail: s.coutts@uq.edu.au
- Conclusions Right-skewed fecundity distributions have the potential to slow spread rates, while preferentially releasing seeds in dry windy conditions is likely to increase spread rates. The net effect of these processes is an open question.

Keywords Cone production - Individual variation · Pinus nigra . Seed abscission · Linear mixed-effects models . Negative binomial distribution $\cdot$ Seed traps

\section{Introduction}

The details of fecundity, such as its distribution within a population (Clark et al. 2001) and timing (Soons and Bullock 2008), can have important consequences for population persistence and spread. For most forest species, these dynamics have been well described at stand or regional scale (Oliver and Larson 1996). Studying the variation of fecundity in populations established outside of the species' native range can give great insights into the species' response in different environments (Dehlin et al. 2008). This is particularly important considering many conifer species, including Mediterranean pines, are invading large parts of the world (Richardson and Rejmanek 2004). Further, the reproductive ecology of Pinus species is an important predictor of their invasiveness (Rejmánek and Richardson 1996).

This study describes the reproductive ecology of an invasive population of Pinus nigra at Mt Barker, New Zealand. Pinus nigra is a masting species, with highly productive mast years occurring once every 3-5 years in British and French populations (Kerr 2000; Kerr et al. 2008; Boulant et al. 2009). Differences in cone production between low and high coning years can be dramatic. In an invasive French population trees averaged 33 cones in low 
years and 757 cones in mast years (Boulant et al. 2009). Although detailed studies of its reproductive ecology have been undertaken near its native range in Europe (Southern France) and in Britain (Kerr 2000; Kerr et al. 2008), far less is known about the reproductive ecology of P. nigra in its invasive range in the southern hemisphere.

The distribution of fecundities within many plant populations is often right skewed, with a few highly fecund individuals producing most of the seed (Cook and Lyons 1983; Scheiner 1987; Bullock 1989; Herrera 1991; Herrera and Jovani 2010). Further, in perennial plants fecundity hierarchies can persist through time, i.e. it is the same individuals that are highly fecund each year (Herrera and Jovani 2010). This leads to a few individuals producing many more seeds over their lifetime than the majority of the population. These large variations in total lifetime fecundity between individuals have the potential to substantially reduce spread rates (Clark et al. 2001).

In the genus Pinus, seeds are often released as cones dry out (cones are xerochastic; Greene et al. 2008), thus changes in relative humidity may play a role in seed release. The mechanism behind Pinus species cone response to lower humidity is well established (Dawson et al. 1997; Reyssat and Mahadevan 2009), and several cases have documented dry conditions promoting seed abscission in conifer species. In a British population of $P$. nigra, lower relative humidity increased seed release rates (Kerr et al. 2008), while seed release in a Mediterranean population of $P$. halepensis was strongly correlated with seasonal hot dry winds (Nathan et al. 1999). Also, North American west coast populations of the spruce Picea sitchensis open their cones when drying air descends from nearby mountains (Harris 1969).

The relationship between relative humidity and seed release may be especially important where strong winds are also dry. Then, if $P$. nigra does release more seeds when relative humidity is low, a disproportionate number of seeds may be released when wind speeds are higher, causing higher spread rates (Nathan and Ne'eman 2004). This effect is potentially very important at our study site in New Zealand; the prevailing wind from the northwest is warm, dry, and much stronger than winds from other directions (Caplat et al. 2012b). Wind itself may also play a role in seed release, both increasing evaporative loss and mechanically loosening seeds from cones (Greene et al. 2008).

Pinus nigra may disperse some seeds still inside its cones when it drops them at the end of each dispersal season. In a British population, Kerr et al. (2008) found $46 \%$ of seeds dispersed in this way. If this mode of dispersal occurs more generally, then assuming all seeds are released and enter the wind dispersal kernel may overestimate spread. The data by Kerr et al. (2008) suggests that nearly half of available seeds would remain in the cone and drop near the parent. This would reduce the amount of seed available for long distance dispersal, which has been shown to be important in driving spread in the Mt Barker population of P. nigra (Buckley et al. 2005).

We undertook a detailed study of the timing and distribution of fecundity in an invasive population of $P$. nigra at Mt Barker, New Zealand. We compare our results with those from studies of $P$. nigra nearer it home range in Europe, to see how its reproductive ecology changes between ranges. We also discuss the implications of our results for population spread, a process which is of fundamental importance to understanding and managing invasive plants (Caplat et al. 2012a; Richardson and Pysek 2006).

\section{Method}

We first describe the study species and main study area (Mt Barker), and then describe field methods, outlining how seeds and cones were counted and/or trapped and how meteorological data was collected. This is followed with a description of the data analysis. We outline how distributions were fit to cone production within the population and the distribution of seeds per cone. We then describe the analysis of cone opening and seed release, and how seed release was related to relative humidity and windiness. All data analyses were carried out in the R statistical package, and unless otherwise stated all functions used were part of the "base" or "stats" libraries (R Core Development Team 2010).

\subsection{Study species}

The main subspecies of $P$. nigra present at Mt Barker is P. nigra Arn. ssp. laricio (Buckley et al. 2005), but a minority of pine at Mt Barker also display characteristics of subspecies nigra Arn. The genetic structure of the population has not yet been studied, and hereafter we refer to all pines in the Mt Barker population as P. nigra. Pinus nigra is a wind-dispersed species, with winged seeds that have a low mass relative to other Pinus species (Rejmánek and Richardson 1996). Our dataset contained 15 trees at Mt Barker that did not produce cones in 2008 but did in 2009. From these trees, we calculate cone production started at a median age of 16 years, with trees as young as 13 and as old as 19 observed to produce cones for the first time. Pinus nigra produce one growth node per year and can be aged by counting nodes (Buckley et al. 2005).

\subsection{Study area}

Our main study population of P. nigra is at Mt Barker, Canterbury high plains, South Island, New Zealand 
$\left(17,135^{\prime} 15^{\prime \prime} \mathrm{E}, 4,321^{\prime} 30^{\prime \prime} \mathrm{S}, \sim 620 \mathrm{~m}\right.$ above sea level). Precipitation at Lake Coleridge (1.5 km away) is $907 \mathrm{~mm}$ annually, and mean temperature at the site is $8.3^{\circ} \mathrm{C}$ (Caplat et al. 2012b). The population began as a shelter belt planted in approximately 1910 (Buckley et al. 2005) and is currently invading a lightly grazed grassland.

\subsection{Cone counts}

In 2008 , all $P$. nigra $>1.5 \mathrm{~m}$ tall in six randomly placed $30 \times$ $30 \mathrm{~m}$ low-density plots (densities ranged from 100 to 155 trees $\mathrm{ha}^{-1}$ ) were tagged and had their heights and ages recorded. To estimate the number of female cones (hereafter just cones), they were counted by two separate observers. The average across both counts was used to estimate the number of cones. In 2009, the same six plots used in 2008 were re-censused. Data were also obtained from repeated cone counts of 20 trees at Lake Ruataniwha $(160 \mathrm{~km}$ south west of Mt Barker and $550 \mathrm{~m}$ above sea level). These were carried out annually between the years of 1993 and 1997; all trees were 16 years old in 1993 and 20 years old in 1997, the last year of data collection at Lake Ruataniwha (Ledgard, unpublished data). Distributions of cone production for Mt Barker were fit to trees between the ages of 16 and 24 years old, with a median age 19. Most trees younger than 16 years of age were observed to carry few cones and the upper limit (24 years old) is the oldest observed tree in the low-density plots.

\subsection{Seed collection and cone harvest}

To measure seed release rates, 10 trees with no open cones, located at least $10 \mathrm{~m}$ from any other tree with cones, had eight $1 \times 1 \mathrm{~m}$ seed traps placed under their canopy edge (Fig. 1a). Seed traps were made from a fine plastic mesh suspended above the ground on four legs, with a weight placed in the centre of the mesh to stop the mesh moving in the wind (Fig. 1b). Seed traps had an open top, possibly allowing birds to predate seeds, but no seed predation from seed traps was observed and birds were never seen near the traps. Seed traps were deployed on the 17th of July 2009, just before the first open cones were observed. Seed traps were checked six times, the final check occurring 60 days after deployment on the 15th of September 2009. Average period between checks was 10 days but varied between 4 and 15 days depending on weather. At each check, the number of seeds was counted and each seed was crushed to determine if the embryo was present.

To document seed abscission from the northwest and southeast aspects separately, five cones from each aspect were harvested six times throughout the dispersal season from the same 20 trees (hereafter called harvest trees). Harvest trees were selected by identifying the first 20 trees encountered on a randomly placed transect that were both unshaded by neighbours and had enough cones to allow multiple harvests. The first harvest occurred on the 16th of July 2009 and the final harvest on the 24th of September 2009. Average period between harvests was 14 days, but varied between 8 and 20, depending on weather and site accessibility. When cones were harvested the proportion of scales open was visually assessed as being $0 \%, 0-20 \%$, $20-40 \%, 40-60 \%, 60-80 \%$ or $80-100 \%$ (hereafter referred to as \%open). Scales were counted as open if the gap between the scale and the underlying scale was visible. Harvested cones were placed in individual bags and put in a $75^{\circ} \mathrm{C}$ oven until all the scales opened. Once each cone had opened, all seeds where removed, counted and crushed to test for the presence on an embryo (as for the seed traps). At the start of the 2008 dispersal season, an additional 10 trees had between 18 and 24 cones harvested from them, these cones had their seeds counted as in 2009 .

\subsection{Meteorological data}

Relative humidity and horizontal wind speed were measured using Campbell Scientific humidity probe and CSAT3 sonic anemometers. Relative humidity was recorded $1.5 \mathrm{~m}$ above the ground, while wind speeds were recorded $8.3 \mathrm{~m}$ above the ground. Twenty-min averages of relative humidity and wind statistics were recorded continuously throughout the dispersal season with a Campbell Scientific Data Logger.

\subsection{Distribution of fecundity within and between years}

To determine the distribution of fecundity within each year, and how it varied between years, we used the data from both
Fig. 1 a Schematic layout of seed traps around a tree and $\mathbf{b}$ diagram of seed trap design

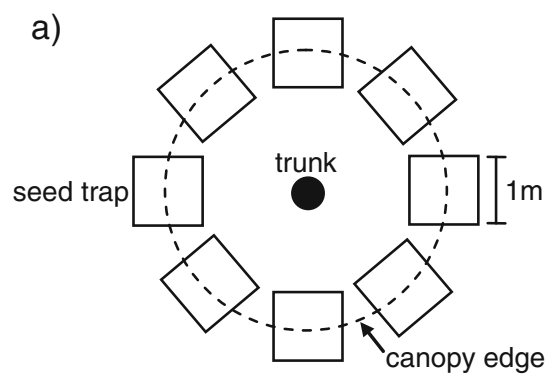

b)

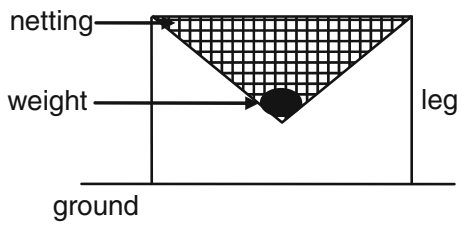


Lake Ruataniwha and Mt Barker. Five potential distributions were fit to cone production within each year; negative binomial, exponential power, log normal, and two mixed distributions that permitted greater flexibility in fitting the data (gamma $+\exp$ and Weibull + exp). Because the two mixed distributions are not standard, we will explain them more fully. The gamma + exp distribution was

$f(x)=\operatorname{Gamma}\left(x, k_{g}, s_{g}\right) p_{g}+\lambda e^{-\lambda x}\left(1-p_{g}\right)$

where, $f(x)$ was the probability density of $x$ cones; $k_{g}$ and $s_{g}$ were, respectively, shape and scale parameters for the gamma distribution; $\lambda$ controlled how quickly the negative exponential part of the distribution approached 0 ; and $p_{g}$ was the portion of gamma distributed fecundities. The Weibull $+\exp$ distribution had a similar form (Eq. 3.2).

$f(x)=\operatorname{Weibull}\left(x, k_{w}, s_{w}\right) p_{w}+\lambda e^{-\lambda x}\left(1-p_{w}\right)$

where, $k_{w}$ and $s_{w}$ were shape and scale parameters for the Weibull distribution and $p_{w}$ was the portion of fecundities that were Weibull distributed. We also fit standard gamma and Weibull distributions but these always had likelihoods extremely close to 0 .

Distributions were fit using maximum likelihood with either the fitdistr function (Venables and Ripley 2002) or numerically with the optim function, depending on whether or not the distribution was available in the fitdistr function. Akaike information criterion (AIC) was calculated for each model.

To test if individual P. nigra maintain their relative positions in the fecundity distribution, we followed the approach of Pinheiro and Bates (2000) to analyse repeated measures of subjects (section 4.1 and 4.2 of that book). Because we required a longer time series, this analysis only uses the data from Lake Ruataniwha. Using the linear and nonlinear mixed effects models (nlme) library (Pinheiro et al. 2010), we fit a linear model predicting cone production with year, using tree as a random factor. If trees had different intercepts but could share the same slope, then any tree that had a higher cone count in 1 year must have had a higher cone count in all years, i.e. their fecundity hierarchy persisted over time.

To test whether the number of filled seeds per cone changed between years, we used seed counts of cones that had not yet opened from 2008 (12 trees, 18-24 cones from each tree) and 2009 (18 harvest trees, 7-20 cones per tree). The same trees were not sampled in each year. We modelled the mean number of viable seeds per cone for each tree $(n=30)$ and an ANOVA was used to test the effect of year on the mean number of filled seeds per cone.

To describe the distribution of mean filled seeds per cone within the population, we used a beta distribution. We fit a beta distribution with mode of $m$ and a shape parameter of $\beta$ to the mean number of seeds per cone, with each tree as a separate data point. We rescaled the beta distribution so that it was not restricted to a $[0,1]$ interval. The fitdistr function (Venables and Ripley 2002) used maximum likelihood to fit the beta distribution.

\subsection{Analysis of the timing of seed release}

Taking the upper limit for each interval of \%open as a proportion (i.e. $0,0.2,0.4,0.6,0.8,1$ ), we used a linear mixed effects model to predict logit (upper limit of \%open) with time and aspect, using tree as a random effect. Following Warton and Hui (2011), we used the logit transformation to linearise the response because predictions could be easily back transformed to the real scale. The lowest and highest \%open values, 0 and 1 , were changed to 0.0001 and 0.9999 , respectively, so the transformed values would not be infinity. We fit the models in lme4 (Bates and Maechler 2010) with a Gaussian error distribution. When testing random effects, models were fit with restricted maximum likelihood. We used likelihood ratio tests to establish if each tree had a different intercept for aspect and slope for time. We used AIC to determine which fixed effects were best supported by the data (fitting models with maximum likelihood).

We focused our analysis of seed release timing only on full seeds (those with a completely formed embryo) because they had the potential to germinate, and it was unknown if empty and full seeds dispersed at the same time or had the same probability of being caught by seed traps. Sampling effort was uneven between trees and time periods because periods between trap checks varied and some traps fell down during heavy snow or high wind. To correct for this, counts from traps were converted to full seeds per trap day (full seeds/trap day), where a trap day is one trap standing for 1 day. We used mixed effects models implemented with the nlme library (Pinheiro et al. 2010) to predict $\ln$ (full seeds/trap day+ 1) in each sample period.

Time was included as a covariate and we used days since the sampling started (DSS) as our measure of linear time. We also fit a quadratic term for time, allowing seed capture rate to increase at the start of the season as cones began to open, and decrease at the end of the season as trees held fewer and fewer seeds. Both DSS (linear time) and DSS ${ }^{2}$ (quadratic time) were centred on the mid-point of the dispersal season. Relative humidity was measured as the proportion of dry days (DD), defined as any day with an average relative humidity under $50 \%$. The windiness of a sample period was measured as the proportion of days with a mean horizontal wind speed lower than the dispersal season average (WUA). Several other measures of relative humidity and windiness were tried, proportion of days with an 
average relative humidity under $60 \%$, proportion of days with a minimum relative humidity under $40 \%$, average relative humidity and average horizontal wind speed. All measures produced similar results and lead to the same conclusions. Using restricted maximum likelihood to fit the models, we used likelihood ratio tests to determine if each tree needed a different slope for days since DSS, proportion of DD and proportion of still days (WUA). We also tested if temporal autocorrelation between adjacent sampling periods needed to be accounted for with a likelihood ratio test on an autoregressive order 1 error process (again models were fit with restricted maximum likelihood). We used AIC to determine which fixed effects were best supported by the data (fitting models with maximum likelihood).

\section{Results}

3.1 Distribution of cone production within and between years

All years showed the same general pattern, many trees produced few cones and a small number of trees produced many cones (Fig. 2). 1996 (Lake Ruataniwha) and 2009 (Mt Barker) were likely mast years, having very high cone production. There were 2 years with very low fecundity 1993 and 1997 (note the scales on the $x$-axis in Fig. 2). Since the trees sampled at Lake Ruataniwha were only 16 years old in 1993 , it is possible that the low cone counts in this year were due to the young age of the trees. The low coning year in 1997 however occurred directly after one of the highest coning years observed. Mean cones per tree (and the mean of the negative binomial distributions, $\mu$ ) was greatest in 2009 at Mt Barker with 278.6 cones per tree, and was just 26 cones per tree in 1997 at Lake Ruataniwha. We found the negative binomial and gamma + exp were the best supported distributions; consistently having the lowest AICs (Table 1).

When interpreting the distributions in Fig. 2, it is important to take into account the age of the trees sampled. Recall that trees used to fit the distributions in Fig. 2 were aged between 16 and 24 years old. Recall also that we observed trees as old as 19 years producing cones for the first time. Thus, some (but not all) of the low coning trees in Fig. 2 will be a result the trees young ages. However, we expect the distributions of cone production we observed to be typical of an invasion front, where trees just reaching maturity will be common. The distributions of cone production at $\mathrm{Mt}$ Barker were observed on the invasion front.

\subsection{Fecundity hierarchies over time}

Correcting for temporal autocorrelation between adjacent years did not significantly improve model performance $(P<0.2)$. Individual trees shared the same slope $(P>0.99)$.

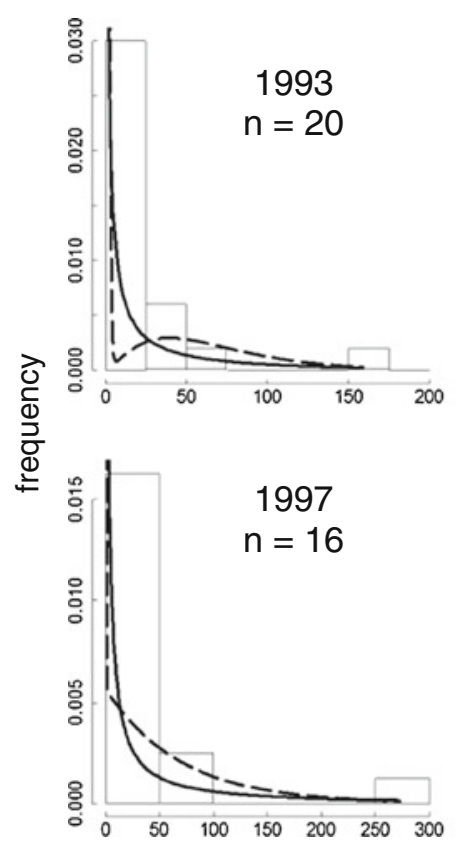

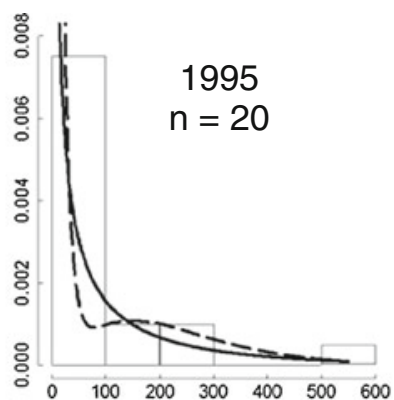
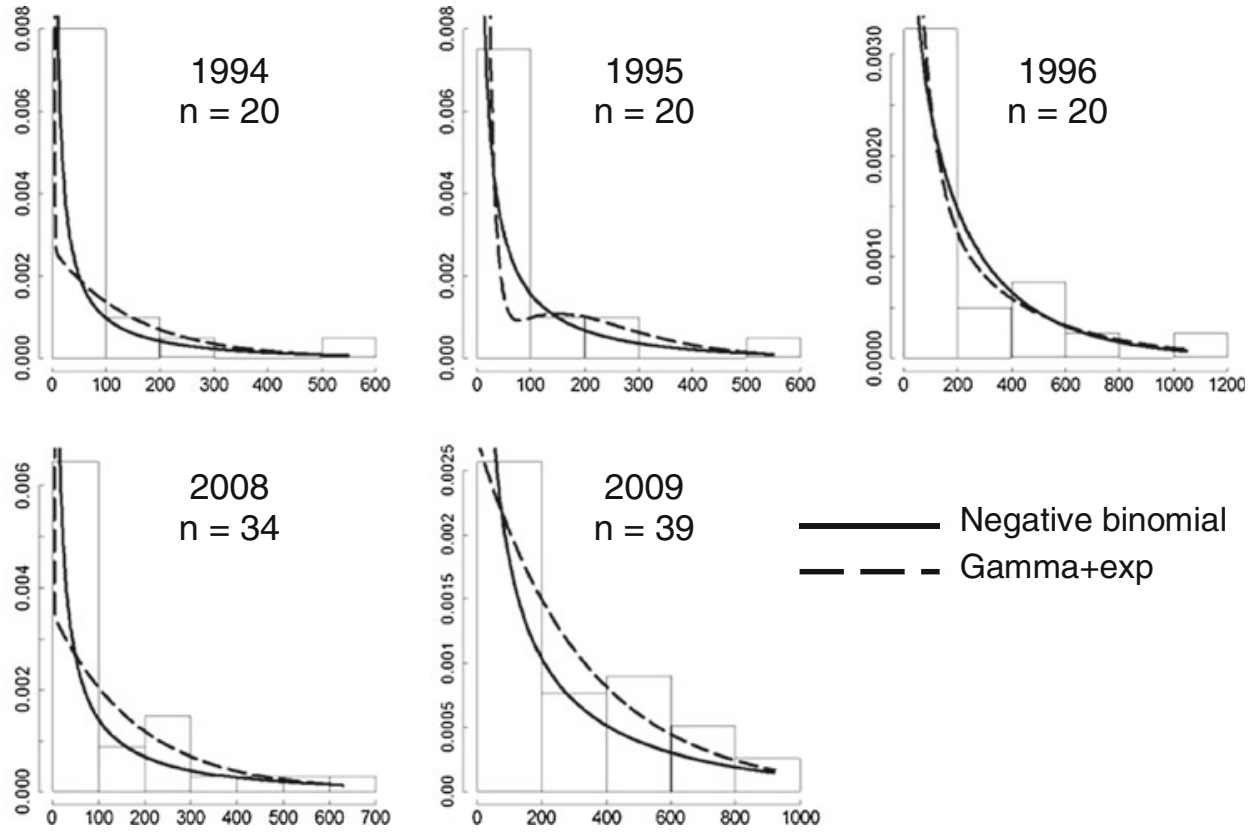

fecundity (cones/tree)

Fig. 2 Histograms show the observed distribution of cones per tree at Lake Ruataniwha (years 1993-1997) and Mt Barker (years 2008 and 2009). Lines show the negative binomial and gamma $+\exp$ fitted distributions. $n$ indicates sample size for the histograms. It is important to note that distributions are fit to the underlying data, not the histogram. Note the different scales on the $x$ and $y$-axes for different years 
Table 1 AIC for each fitted distribution

Lowest AICs are bold, AICs within 10 of the lowest are italicized

\begin{tabular}{lccccc}
\hline Year & Neg. binom. & Exp. power & Log-normal & Gamma + exp Weibull + exp & \\
\hline 1993 & 101.87 & 158.25 & 127.34 & $\mathbf{1 0 0 . 3 2}$ & 110.63 \\
1994 & $\mathbf{1 4 7 . 4 3}$ & 206.79 & 164.86 & 147.81 & 168.53 \\
1995 & $\mathbf{1 9 3 . 6 2}$ & 220.41 & 202.91 & 205.53 & 201.11 \\
1996 & $\mathbf{2 6 0 . 1 1}$ & 262.02 & 262.81 & 263.18 & 266.02 \\
1997 & $\mathbf{8 5 . 0 7}$ & 140.94 & 106.95 & 91.98 & 91.98 \\
2008 & 336.09 & 394.81 & 357.9 & $\mathbf{3 3 5 . 1 2}$ & 349.66 \\
2009 & 498.5 & 521.27 & 520.08 & $\mathbf{4 8 9 . 9 9}$ & 525.27 \\
\hline
\end{tabular}

This was also shown when we fit a separate linear model predicting $\ln$ (number of cones +1 ) with year for each tree using lmList (Pinheiro et al. 2010). The 95\% confidence intervals for the slopes overlapped, but those for the intercepts did not (Fig. 3). Thus, individual trees varied in fecundity (Fig. 3) and they maintain their rank in fecundity over time (tree shared a slope through time). Also note that in Fig. 3, the 95\% confidence limits for the slope of each tree encompassed 0 . Thus, on average, trees cone production did not change over the 5 years recorded.

\subsection{Distribution of mean number of filled seeds per cone} within the population

We found no significant difference between the mean number of filled seeds per cone in 2008 and 2009 at the population level $(P>0.11)$; where differences between individual trees could swamp any effect of year. We did not have sufficient multi-year data on the individual trees to partition variance between the effect of tree and year.

Because our sample size was low and the $p$ value small, we explored the data further, fitting an intercept to the mean number of filled seeds per cone for each tree (log transformed) using lmList (Pinheiro et al. 2010). Much of the difference between 2008 and 2009 was driven by just two trees sampled in 2009 (2009C and 2009M) that had very low numbers of filled seeds per cone (Fig. 4). This further suggests that the mean number of filled seeds per cone did not change markedly between years at the population level.

There was little evidence for a difference between years so we fit a beta distribution to the combined 2008 and 2009 data (Fig. 5). We calculated the mean number of filled seeds per cone for each tree. Individual trees had, on average, a mean of 34 filled seeds per cone, with a range of 4.5-70.7. The mode of the fitted beta distribution, $m$, was 29.4 with a $\beta$ parameter of 6.34 .

\subsection{Timing of cone opening}

In the model predicting logit (upper limit of \%open class) the interaction between aspect and time had to be retained in the random effects $(P<0.001)$. Thus, the difference in cone opening rates between northwest and southeast aspects
Fig. 3 A linear model predicting $\ln ($ number of cones +1 ) with year, fit to each tree separately using $1 \mathrm{mList}$. The intercept for each model is shown on the left and slope on the right. Bars $95 \%$ confidence intervals

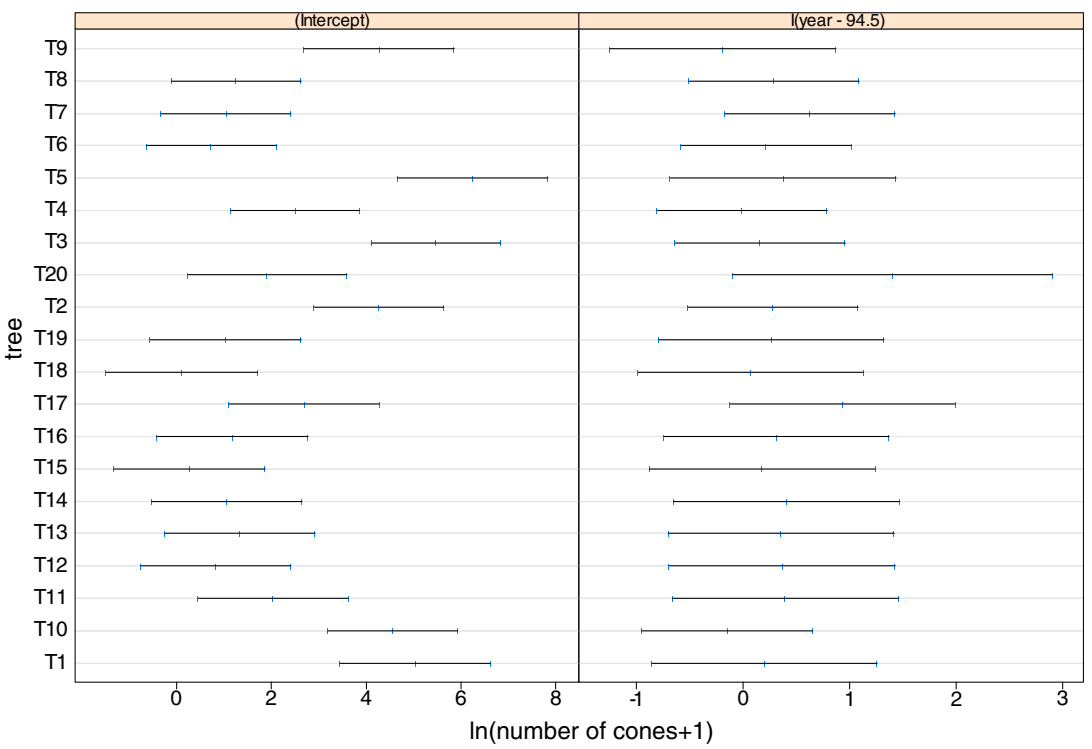




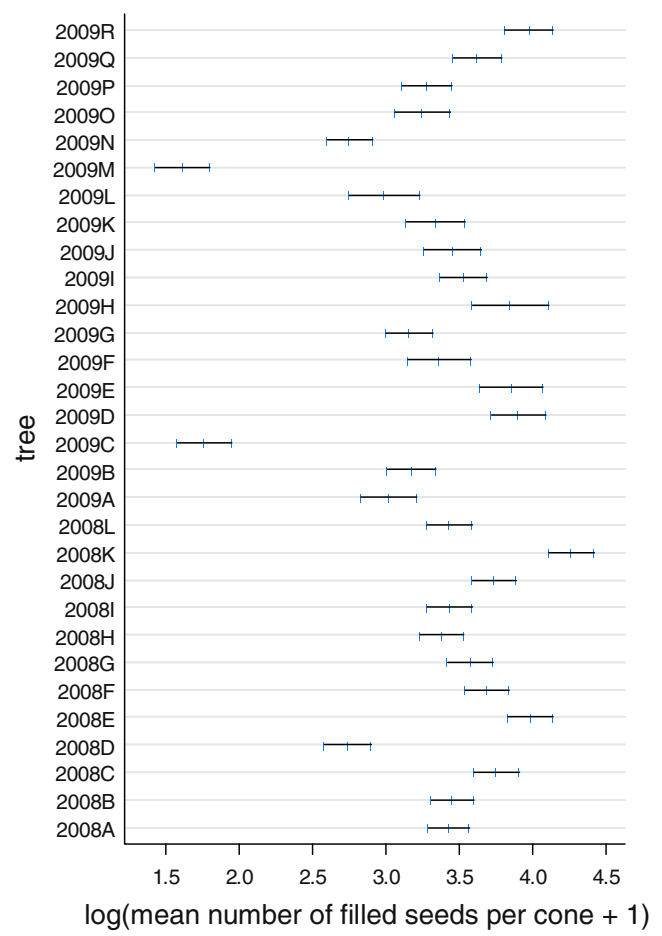

Fig. 4 Central ticks are the mean number of viable seeds per cone fit to each tree, black lines give the $95 \%$ confidence limits. Trees with labels starting with 2008 (e.g. 2008A) were sampled in 2008 and trees with labels starting in 2009 were sampled in 2009

changed through time and was different between trees. Models including an interaction between aspect and time in the fixed effects had the same amount of support as models that $\operatorname{did} \operatorname{not}($ AIC with interaction $=6,701$, AIC without interaction $=$ 6,700.2). Diagnostic quantile-quantile plots showed that the random and fixed effects were normally distributed. A plot of fitted values versus residuals for each tree showed that there was some reduction of variance for high values of \%open. Due to its greater simplicity, we used the model without the interaction in the fixed effects to demonstrate how cones opened through time. Plots for all harvest trees showed the same pattern and for clarity we only show one example (Fig. 6a).

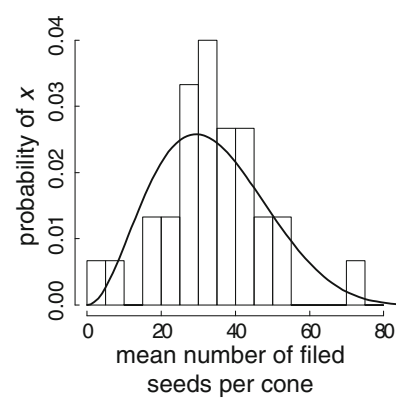

Fig. 5 Beta distribution (curve) and histogram of mean filled seeds per cone. Data from 2008 to 2009 were combined, with each tree as a separate data point, $n=30$ for histogram
Cones on the northwest aspect of trees started to open in mid to late July, while cones on the southeast side began to open about 2 weeks later in early August (difference between solid and dotted lines in Fig. 6a). Throughout August, cones opened quickly (steep sections on lines in Fig. 6a) and by September the majority of cones on all seed harvest trees, for both aspects, were greater than $60 \%$ open, with a high proportion more than $80 \%$ open. Mirroring the cone opening results, by September seed harvest trees had very few filled seeds left in their cones for either aspect (last two harvest dates in Fig. 6b).

\subsection{Timing of seed release}

Models predicting seed capture rates from seed traps, $\ln$ (full seeds/trap day +1 ), that corrected for temporal auto correlation did not fit the data significantly better than models that did not $(P>0.99)$. Trees only required a separate slope for proportion of DD $(P<0.03)$, but could share a slope for proportion of days with lower than average wind speed, WUA $(P>0.53)$. This suggests that trees responded differently to relative humidity but not wind.

We found that models containing an interaction between DD and either DSS or WUA in the fixed effects had equal AIC support (Table 2). The model without any interaction in the fixed effects had similar support to ether of the models that included an interaction (Table 2). Models without either or both DD and WUA had less support from the data.

To demonstrate the size of the effects for DD and WUA, we use coefficients from the model with fixed effects DSS + $\mathrm{DSS}^{2}+\mathrm{WUA}+\mathrm{DD}$, because it has the best AIC support and its simplicity allows for easier interpretation. On average, for every 0.1 increase in the portion of dry days, 0.67 extra filled seeds/trap day were caught, for reference median filled seeds/trap day across all trees was 0.53 . On average, for every 0.1 increase in the proportion of days with a lower than average wind speed, 0.46 less filled seeds/trap day were caught.

\section{Discussion}

European populations of $P$. nigra are known to have highly variable fecundity through time (Kerr et al. 2008; Boulant et al. 2009). Our data supports this for New Zealand populations, with two very high coning years recorded in 1996 (at Lake Ruataniwha) and 2009 (at Mt Barker) and a very low coning year in 1997 (at Lake Ruataniwha). In support of previous work (Cook and Lyons 1983; Scheiner 1987; Bullock 1989; Herrera 1991; Herrera and Jovani 2010), at both Mt Barker and Lake Ruataniwha, most trees produced relatively few cones and a few trees produced many (distribution was right skewed). 
Fig. 6 a \%open of each cone harvested from the northwestern (circles) and southeastern (crosses) aspects of seed harvest tree 11. Lines show the \%open predicted by a linear mixed effects model. The solid line shows the prediction for cones on the northwest aspect and the dashed line shows the prediction for cones on the southeast aspect. b Mean number of filled seeds per cone for each aspect of each seed harvest tree in each time period a

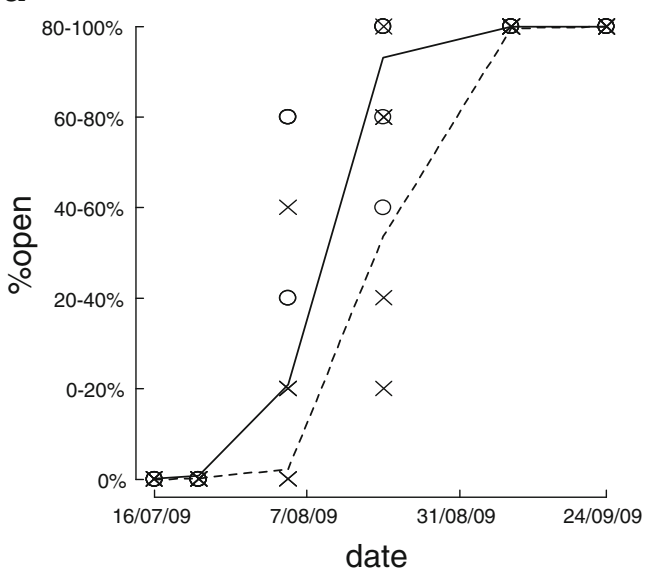

b

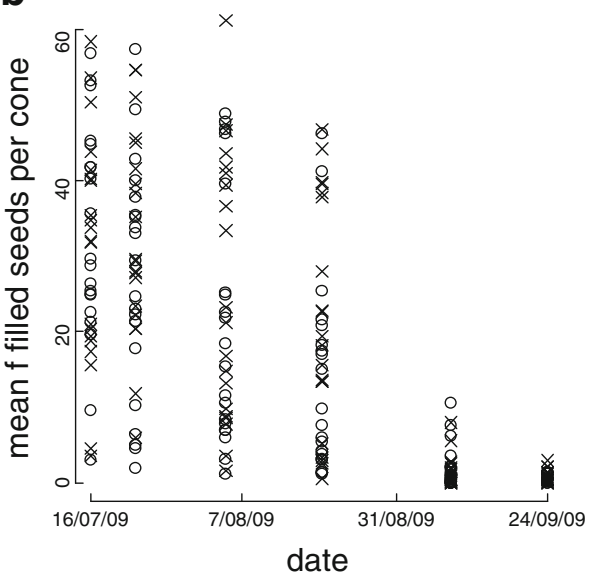

Despite high variability in the average number of cones produced between years, the best supported within-year fecundity distribution was consistently a negative binomial or gamma + exp. These distributions could just happen to be a good fit for the data and have no deeper biological meaning. This is especially true of the gamma + exp distribution, which could take on a large number of shapes. However, the fact that the negative binomial distribution was a consistently good fit suggests that some trees are more able to produce cones than others. For example, there might be genetic differences between trees, or, cone production could be limited by environmental factors in some trees but not in others (Santos-del-Blanco et al. 2010). To see why this might lead to a negative binomial distribution, consider the following. Each tree has a certain number of potential sites for cone formation. If each potential site becomes an actual cone with a constant probability, and that probability is the same for all trees, then we would expect the number of cones per tree across the whole population to be Poisson

Table 2 Fixed effects in linear mixed effects models predicting seed catch rates, $\ln ($ full seeds/trap day +1 ), and the AIC of the resulting models

\begin{tabular}{|c|c|}
\hline Model & AIC \\
\hline $\mathrm{DSS}+\mathrm{DSS}^{2}+\mathrm{WUA}+\mathrm{DD}+\mathrm{DD} * \mathrm{WUA}$ & 75.68 \\
\hline $\mathrm{DSS}+\mathrm{DSS}^{2}+\mathrm{WUA}+\mathrm{DD}+\mathrm{DD} * \mathrm{DSS}$ & 75.68 \\
\hline $\mathrm{DSS}+\mathrm{DSS}^{2}+\mathrm{WUA}+\mathrm{DD}$ & 74.1 \\
\hline $\mathrm{DSS}+\mathrm{DSS}^{2}+$ WUA & 81.64 \\
\hline $\mathrm{DSS}+\mathrm{DSS}^{2}+\mathrm{DD}$ & 84.51 \\
\hline $\mathrm{DSS}+\mathrm{DSS}^{2}$ & 82.72 \\
\hline
\end{tabular}

Linear and quadratic time, DSS and $\mathrm{DSS}^{2}$, were covariates that had to be included in all models to account for trees holding less and less seed as the dispersal season progressed. DD was the proportion of dry days and WUA was the proportion of days with horizontal wind speed under the season average. All models allowed trees to have separate slopes for $\mathrm{DD}($ random effects $=\mathrm{DD} \mid$ tree $)$ distributed. However, if the probability of producing a cone at each potential site varies between trees, then we would expect the number of cones per tree to follow a negative binomial distribution (Clark 2007, appendix F.1.2 and F.1.3). Previous work on a Mediterranean shrub has found fecundity to be log-normal distributed (Herrera and Jovani 2010). Our data never supported the log-normal distribution as the best, suggesting that mechanisms structuring fecundity hierarchies are different in different species and environments.

As has been reported for other species (Herrera and Jovani 2010), P. nigra individuals that produced high numbers of cones relative to other trees in 1 year tended to do so in all years. Combined with a right-skewed fecundity distribution, this means some individuals would produce many more seeds over their lifetime than others. This right-skewed variance in lifetime reproductive output means that most individuals in the population produce few seeds. As a result, those individuals that disperse far ahead of the main invasion front are unlikely to become new invasion foci, the absence of which can dramatically slow spread (Clark et al. 2001).

In Britain, P. nigra can drop its cones while they still contain nearly half their seeds (Kerr et al. 2008), substantially reducing the number of seeds available for mid- to long-distance dispersal. This was not the case at Mt Barker where trees had released almost all of their seeds by mid September, several weeks before they shed their cones. However, Pinus cones can re-close in wet conditions (Dawson et al. 1997; Kerr 2000). This was also the case at Mt Barker where cones re-closed during persistent rain at the very end of the dispersal season (mid September). If it had been wetter throughout the dispersal season, cones may have re-closed with seeds still in them, increasing the chance that some seeds would remain unreleased until cones were dropped.

Supporting reports from other conifer populations (Harris 1969; Nathan et al. 1999; Kerr et al. 2008), P. nigra at Mt Barker release more seeds during dry and windy periods. 
This may be especially important at Mt Barker, where warm dry northwest winds predominate, and tend to be stronger than winds from other directions. If more seeds are released during these northwest winds, there is a greater chance that seeds will disperse long distances because wind speed strongly affects long-distance dispersal in $P$. nigra (Caplat et al. 2012b). Small increases in long-distance dispersal can dramatically increase the spread rate of pines (Higgins and Richardson 1999). Therefore, wind statistics averaged over whole dispersal seasons could underestimate spread rates. Although the mechanism differed, a similar conclusion was reached for Carduus acanthoides and Carduus nutans (Jongejans et al. 2007).

Cone production in P. nigra at Mt Barker and Lake Ruataniwha was heavily right skewed and fecundity hierarchies were persistent through time. Thus, a few trees will have much higher lifetime reproduction than the majority of the population. This variance in lifetime reproductive success can dramatically slow spread (Clark et al. 2001). Seed release at Mt Barker was correlated with dry and windy conditions. This suggests that more seeds were released when conditions for long distance dispersal were favourable, which would be expected to increase spread rates (Caplat et al. 2012b). Which of these two effects dominate will depend on how right skewed the distributions of lifetime reproduction are and how much additional long distance dispersal is caused by preferentially opening cones in dry windy conditions.

Acknowledgements Thanks to Scion for providing lab space in Christchurch and equipment, with a special thanks to Alan Leckie for favours too numerous to mention. Also thanks to Landcare Research in Lincoln for providing randomised sampling plots. Thanks to Gordon Baker for sharing his knowledge of pines in New Zealand.

Funding This study was funded by the Australian Research Council (DP0771387) and an Australian Research Fellowship to YMB. KC was supported by funds from these grants. PC was funded through an Australian Research Council-OCE Postdoctoral Fellowship. SC was funded by an Australian Research Council-linkage scholarship. NL was funded by Scion.

\section{References}

Bates D, Maechler M (2010). lme4: Linear mixed-effects models using S4 classes. R package version 0.999375-35. http://CRAN.R-project.org $/$ package $=1 \mathrm{me} 4$

Boulant N, Garnier A, Curt T, Lepart J (2009) Disentangling the effects of land use, shrub cover and climate on the invasion speed of native and introduced pines in grasslands. Divers Dist 15:1047-1059

Buckley YM, Brockerhoff E, Langer L, Ledgard N, North H, Rees M (2005) Slowing down a pine invasion despite uncertainty in demography and dispersal. J Appl Ecol 42:1020-1030
Bullock SH (1989) Life-history and seed dispersal of the short-lived chaparral shrub dendromecon-rigida (Papaveraceae). Am J Bot 76:1506-1517

Caplat P, Coutts SR, Buckley Y (2012a) Modeling population dynamics, landscape structure and management decisions for controlling the spread of invasive plants. Ann NY Acad Sci. doi:10.1111/j.1749-6632.2011.06313.x

Caplat P, Nathan R, Buckley Y (2012b) Seed terminal velocity, wind turbulence and demography drive the spread of an invasive tree in an analytical model. Ecology. doi:http://dx.doi.org/10.1890/110820.1

Clark JS (2007) Models for ecological data: an introduction. Princeton University Press, Princeton

Clark JS, Lewis M, Horvath L (2001) Invasion by extremes: POPULATION spread with variation in dispersal and reproduction. Am Nat 157:537-554

Cook RE, Lyons EE (1983) The biology of Viola fimbriatula in a natural disturbance. Ecology 64:654-660

Dawson J, Vincent JFV, Rocca AM (1997) How pine cones open. Nature 390:668-668

Dehlin H, Peltzer DA, Allison VJ, Yeates GW, Nilsson MC, Wardle DA (2008) Tree seedling performance and belowground properties in stands of invasive and native tree species. N Z J Ecol 32:67-79

Greene DF, Quesada M, Calogeropoulos C (2008) Dispersal of seeds by the tropical sea breeze. Ecology 89:118-125

Harris AS (1969) Ripening and dispersal of a bumper western hemlock-Sitka spruce seed crop in southeast Alaska. Note PNW-105. United States Forest Service, Portland

Herrera CM (1991) Dissecting factors responsible for individual variation in plant fecundity. Ecology 72:1436-1448

Herrera CM, Jovani R (2010) Lognormal distribution of individual lifetime fecundity: insights from a 23-year study. Ecology 91:422-430

Higgins SI, Richardson DM (1999) Predicting plant migration rates in a changing world: the role of long-distance dispersal. Am Nat 153:464-475

Jongejans E, Pedatella NM, Shea K, Skarpaas O, Auhl R (2007) Seed release by invasive thistles: the impact of plant and environmental factors. P Roy Soc B-Biol Sci 274:2457-2464

Kerr G (2000) Natural regeneration of Corsican pine (Pinus nigra subsp laricio) in Great Britain. Forestry 73:479-488

Kerr G, Gosling P, Morgan G, Stokes V, Cunningham V, Parratt M (2008) Seed production and seedling survival in a 50-year-old stand of Corsican pine (Pinus nigra subsp laricio) in southern Britain. Forestry 81:525-541

Nathan R, Ne'eman G (2004) Spatiotemporal dynamics of recruitment in Aleppo pine (Pinus halepensis Miller). Plant Ecol 171:123-137

Nathan R, Safriel UN, Noy-Meir I, Schiller G (1999) Seed release without fire in Pinus halepensis, a Mediterranean serotinous wind-dispersed tree. J Ecol 87:659-669

Oliver CD, Larson BC (eds) (1996) Forest stand dynamics. Wiley, New York

Pinheiro J, Bates D (2000) Mixed-effects models in S and S-PLUS. Statistics and Computing Series. Springer, New York

Pinheiro J, Bates D, DebRoy S, Sarkar D, the R Development Core Team (2010) nlme: Linear and nonlinear mixed effects models. R package version 3:1-97

R Development Core Team (2010). R: A language and environment for statistical computing. R Foundation for Statistical Computing, Vienna, Austria. ISBN 3-900051-07-0, URL http://www.R-project.org/

Rejmánek M, Richardson DM (1996) What attributes make some plant species more invasive? Ecology 77:1655-1661

Reyssat E, Mahadevan L (2009) Hygromorphs: from pine cones to biomimetic bilayers. J R Soc Interface 6:951-957 
Richardson DM, Pysek P (2006) Plant invasions: merging the concepts of species invasiveness and community invasibility. Prog Phys Geogr 30:409-431

Richardson DM, Rejmanek M (2004) Invasive conifers: a global survey and predictive framework. Divers Distrib 10:321-331

Santos-del-Blanco L, Zas R, Notivol E, Chambel MR, Majada J, Climent J (2010) Variation of early reproductive allocation in multi-site genetic trials of maritime pine and Aleppo pine. For Syst 19:381-392
Scheiner SM (1987) Size and fecundity hierarchies in an herbaceous perennial. Oecologia 74:128-132

Soons MB, Bullock JM (2008) Non-random seed abscission, long-distance wind dispersal and plant migration rates. J Ecol 96:581-590

Venables WN, Ripley BD (2002) Modern applied statistics with S, 4th edn. Springer, New York

Warton DI, Hui FKC (2011) The arcsine is asinine: the analysis of proportions in ecology. Ecology 92:3-10 